\title{
A importância da Educação Ambiental para o Ensino de Ciências da Natureza: um olhar para o Tempo Comunidade
}

\section{The importance of the Environmental Dimension for the teaching of Natural Sciences: a glimpse into Time Community}

\author{
Danilo Fernandes Lobato (danilo.fernandes65@gmail.com) \\ Universidade Federal de Catalão - UFCAT \\ Fernanda Welter Adams (adamswfernanda@gmail.com) \\ Secretaria Municipal de Educação de Catalão \\ Simara Maria Tavares Nunes (simaramn@gmail.com) \\ Universidade Federal de Catalão - UFCAT
}

\begin{abstract}
Resumo: Na Educação do Campo é preciso que as Ciências da Natureza $(\mathrm{CN})$ sejam trabalhadas com o objetivo de permitir que o aluno do campo compreenda o meio em que vive, sendo as questões ambientais relacionadas ao conhecimento científico primordiais para essa garantia. Para tanto, é preciso um professor que conheça a realidade do aluno do campo e desenvolva práticas que possibilitem reflexões sobre a relação sociedade-natureza a partir dos próprios elementos cotidianos dos povos do campo. Este trabalho propôs avaliar a importância da Educação Ambiental (EA) para o Ensino de CN na EDUCampo/UFCAT. Trata-se de uma pesquisa qualitativa cuja coleta de dados foi realizada por meio de entrevistas com egressas do Curso. Os dados foram tratados através da Análise Textual Discursiva. Neste Curso, no Tempo Comunidade (TC) são propostos temas geradores com o intuito de problematizar o meio e integralizar as discussões das disciplinas num arranjo interdisciplinar, buscando garantir uma prática pedagógica a partir da realidade do campo com o embasamento das CN. Percebeu-se que o TC foi apontado como o principal meio adotado para se trabalhar as questões ligadas ao meio ambiente e tem proporcionado a interdisciplinaridade e a contextualização do conhecimento científico, realizando a discussão da EA por meio de visitas.
\end{abstract}

Palavras-chave: Tempo Comunidade; Ensino de Ciências da Natureza; Formação de Professores; Educação Ambiental.

Abstract: In Rural Education it is necessary that the Natural Sciences (NC) are worked in a way that allows the student of rural education to understand the environment in which he lives, with environmental issues related to scientific knowledge essential for this guarantee. But for that, it is necessary to have a teacher who knows the reality of the student of rural education and develops practices that enable students to reflect on the man-nature relationship based on their own daily elements. This work aimed to evaluate the importance of the Environmental Education for the Teaching of NC in the EDUCampo/UFCAT. It is a qualitative research whose data collection was carried out through interviews with graduates of the Course. The data were treated through Discursive Textual Analysis. In this Curse, in Community Time (CT) are proposed generating tissues with the aim of problematizing the environment and integrating the 
discussions of the disciplines in an interdisciplinary arrangement, seeking to guarantee a pedagogical practice based on the reality of the rural areas based on the NC. It was noticed that CT was identified as the main medium of working on issues related to the environment and has provided interdisciplinarity and the contextualization of scientific knowledge, carrying out the discussion of environmental education, for example, through visits with this focus.

Keywords: Community Time; Teaching of Natural Sciences; Teacher training; Environmental Education.

\section{INTRODUÇÃO}

A Educação do Campo se origina do processo de luta dos movimentos sociais camponeses e apresenta uma intencionalidade maior de construção de uma sociedade sem desigualdades em busca de justiça social (MOLINA e FREITAS, 2011). Neste sentido, Melo, Adams e Nunes (2020) afirmam que a Educação do Campo se configura no cenário da educação brasileira como um processo em constante transformação, de forma a considerar as particularidades presentes no campo e, consequentemente, permear o processo de ensino e aprendizagem dos sujeitos do campo.

Rodrigues e Bonfim (2017), por sua vez, destacam que a Educação do Campo é uma modalidade de ensino que tem como objetivo a educação de crianças, jovens e adultos que vivem no campo. Estudos realizados por Arroyo (2007), Leite (2002) e Munarim (2006) mostram que o campo sempre foi visto como lugar de atraso, uma realidade a ser superada e, por esses motivos, as políticas sociais e educacionais não foram vistas como prioritárias para esses povos. Quando passaram a lhes ofertar a educação escolar, a mesma esteve centrada no modelo da Educação Rural "adequada aos modelos políticos de desenvolvimento econômico efetivados no campo, cujas bases se fundamentavam nos interesses das classes dominantes" (AZEVEDO, 2007, p. 145). Rodrigues e Bonfim (2017) destacam ainda que no decorrer da história essa modalidade educacional sempre foi deixada em segundo plano, não houve um investimento significativo pelos representantes governamentais para que se tivesse uma Educação do Campo condizente com a cultura e a identidade do povo camponês (RODRIGUES e BONFIM, 2017).

Porém, Rodrigues e Bonfim (2017), ao definirem na atualidade a Educação do Campo, destacam que essa não deve ser vista apenas como modalidade de ensino, mas também como uma política pública que possibilita o acesso ao direito à educação de 
milhares de pessoas que vivem fora do meio urbano e que precisam ter esse direito garantido nas mesmas proporções em que é garantido para a população urbana (RODRIGUES e BONFIM, 2017).

Para atender às demandas de professores especializados para as Escolas do Campo e atentos às realidades destes sujeitos e espaços, foi criado o Curso de Licenciatura em Educação do Campo, que forma professores para atuarem junto a esses sujeitos. Esse Curso tem como um de seus princípios uma educação "do" e "no" campo. Esses conceitos, segundo Caldart (2002), surgiram a partir da luta que há décadas vem sendo travada pelos movimentos sociais, que representam uma parcela que sempre esteve excluída do ensino público de qualidade: "No: o povo tem direito a ser educado no lugar onde vive; Do: o povo tem direito a uma educação pensada desde o seu lugar e com a sua participação, vinculada a sua cultura e as suas necessidades humanas e sociais" (CADART, 2002, p. 18).

Com estes princípios e com o objetivo de formar professores para atuarem com este público específico do campo, o Curso de Licenciatura em Educação do Campo funciona de acordo com a Pedagogia da Alternância. Jesus (2011) define a Alternância como período alternado de vivência e estudo na Escola, na Família e na Comunidade. Neste sentido, a alternância passa a exercer uma função metodológica e pedagógica no processo formativo dos educandos. Assim, a organização curricular dessa graduação prevê etapas presenciais, equivalentes a semestres de cursos regulares, ofertadas em regime de alternância entre Tempo Universidade e Tempo Comunidade, tendo em vista a articulação intrínseca entre a educação e a realidade específica das populações do campo (MOLINA, 2017). No Tempo Universidade (TU) os alunos participam das aulas e de outras atividades acadêmicas no âmbito da Universidade e no Tempo Comunidade (TC) desenvolvem trabalhos em comunidades, que incluem desde o diagnóstico da comunidade, a aproximação com as escolas, com a sala de aula até projetos comunitários no sentido de buscar a integração entre escola e comunidade (BRICK et al., 2014).

Portanto, a formação por área de conhecimento, a interdisciplinaridade e a alternância entre Tempos Comunidade e Tempos Escola/Universidade (Pedagogia da Alternância) compõem o conjunto de elementos que definem as Diretrizes para a Licenciatura em Educação do Campo, o que remete à necessidade de se estabelecer 
reflexões e diálogos sobre os limites e as possibilidades da consolidação de tais diretrizes no âmbito da formação de professores/as e da ação docente nas escolas do campo (BRITTO e SILVA, 2015).

Assim, a Licenciatura em Educação do Campo pretende formar educadores para uma prática docente integral, oferecendo condições de trabalho na gestão dos processos de ensino e aprendizagem que acontecem na escola e no seu entorno (LOPES e BIZERRIL, 2014). Nesse contexto, destaca-se que na Educação do Campo o Ensino de Ciências da Natureza tem suas especificidades em relação a outras áreas do conhecimento (MELO, ADAMS e NUNES, 2020). Quanto ao Ensino de Ciências na Educação do Campo é importante que "[...] os futuros educadores do campo aprendam a ensinar ciências da vida e da natureza baseando-se em contextos de vivência e de significados para os estudantes das comunidades em que vivem e educam” (LIMA, PAULA e SANTOS, 2009, p. 114).

A cultura e a própria relação que estes sujeitos estabelecem com a terra requerem que estes significados e significantes sejam incorporados no planejamento de aulas (ENISWELER, KLIEMANN e STRIEDER, 2015). Isso ocorrerá por meio de uma formação inicial dos professores que os possibilite lidar com essas especificidades já em seu processo de formação, por meio da discussão de metodologias e recursos didáticos que garantam o processo de ensino e aprendizagem, até a discussão das especificidades da Educação do Campo (MELO, ADAMS e NUNES, 2020). Corroborando com essa reflexão, Brick et al. (2014, p. 30) afirmam que:

Formar professores de ciências não apenas para atuar no campo, usando o campo meramente para fins de contextualização do ensino, mas para atuar na Educação do Campo - considerando efetivamente seus princípios, especificidades e demandas - exige necessariamente a articulação entre a constituída área de Educação em Ciências e a emergente área de Educação do Campo.

Desta forma, vê-se que o Ensino de Ciências da Natureza tem especificidades de aprendizagem em relação aos alunos da Educação do Campo, uma vez que esses alunos podem fazer uso do conhecimento científico construído na escola em sua realidade, qual seja, o trabalho com a terra. Assim, acredita-se na necessidade da diversificação do Ensino de Ciências de forma que esse proporcione ao aluno a interpretação do mundo em que vive, ou seja, a sua comunidade e o seu modo de viver/produzir. Sobre isso, Silva et al. (2019, p. 224) afirmam que: 


\begin{abstract}
A escola do campo é o espaço em que se produz o conhecimento a partir da cultura e do modo de vida. Sendo assim, o ensino de ciências deve estar estruturado e pautado em uma perspectiva que valorize o contexto da comunidade. A partir dessa perspectiva, as instituições de educação do campo devem ter suas propostas pautadas em um ensino que atenda as especificidades e valorize a identidade do povo campesino.
\end{abstract}

Tenório et al. (2019) também afirmam que o Ensino de Ciências nas escolas do campo amplia a visão do mundo no qual o aluno está inserido, levando-o a compreender os problemas de contexto social.

Nesse contexto, destaca-se a necessidade de inserção da Educação Ambiental na Educação do Campo, uma vez que se acredita que a associação entre o Ensino de Ciências e a Educação Ambiental permitirá que o aluno realize a interpretação do mundo de forma a valorizar a sua cultura, a terra e seu modo de vida, podendo agir sobre sua realidade com base nestes conhecimentos científicos e ambientais.

Segundo Loureiro (2008), a Educação Ambiental nos propicia apreender “as especificidades dos grupos sociais, o modo como produzem seus meios de vida, como criam condutas e se situam na sociedade, para que se estabeleçam processos coletivos pautados no diálogo, na problematização do mundo e na ação", visto que somente as transformações das condições simbólicas e materiais podem exprimir "a concretude do ato educativo na superação das formas alienadas de existência e das dicotomias entre sociedade-natureza" (LOUREIRO, 2008, p. 7-8).

Mas, para tanto, é preciso um professor que conheça a realidade do aluno do campo e desenvolva práticas que possibilitem que os estudantes reflitam sobre a relação sociedade-natureza a partir dos próprios elementos cotidianos, já que os alunos da Educação do Campo estabelecem uma relação direta com a natureza e o meio ambiente devido ao seu modo de vida.

Para Torales (2013), o professor é o responsável pela execução da Educação Ambiental e o faz a partir de seus conhecimentos, representações e intencionalidades no que se refere à educação e à problemática ambiental. Assim, acredita-se que seja de extrema importância que os profissionais da área de educação vivenciem discussões sobre temáticas ambientais em suas formações, fundamentadas nas atividades de ensino, pesquisa e extensão. E espera-se que esta formação ambiental seja garantida não somente no papel, mas também na teoria/prática. 
A partir do exposto, este trabalho se propôs a avaliar a importância da Educação Ambiental para o Ensino de Ciências da Natureza no Curso de Licenciatura em Educação do Campo (EDUCampo) da Universidade Federal de Catalão (UFCAT). Para isso, foi realizada uma pesquisa de caráter qualitativo, na qual foram entrevistadas seis egressas da primeira turma do Curso com vistas a sondar o processo de formação inicial docente com Habilitação em Ciências da Natureza na perspectiva da relação Ensino de Ciências e Educação Ambiental.

\section{METODOLOGIA}

Esta pesquisa faz parte do Projeto de Pesquisa intitulado "ENSINO DE CIÊNCIAS: realidade e a formação de professores", aprovado pelo Comitê de Ética em Pesquisa da Universidade Federal de Catalão, sob o Parecer consubstanciado CEP de número 2.210.132. Os sujeitos desta pesquisa foram seis egressas da primeira turma do Curso de Licenciatura em Educação do Campo desta Instituição. Antes de se dar início à coleta de dados, foi lido o TCLE (Termo de Consentimento Livre e Esclarecido) com cada participante e após a assinatura disponibilizou-se uma cópia do documento a cada uma. Tal procedimento ético realça a credibilidade e o cuidado com a pesquisa.

Trata-se de uma pesquisa de caráter qualitativo que tem em sua gênese os questionamentos sobre como está ocorrendo a formação de professores dentro da perspectiva ambiental no Curso de Licenciatura em Educação do Campo, Habilitação em Ciências da Natureza, da Universidade Federal de Catalão (EDUCampo/UFCAT).

De acordo com Bogdan e Biklen (1994, p. 49), "a abordagem da investigação qualitativa exige que o mundo seja examinado com a ideia de que nada é trivial, que tudo tem potencial para constituir uma pista que nos permita estabelecer uma compreensão mais esclarecedora do nosso objeto de estudo". Esse tipo de pesquisa começou a ser praticada mais efetivamente a partir dos anos setenta (1970), quando as agências federais de financiamentos em pesquisa manifestaram interesse por propostas que tinham a abordagem qualitativa como caráter avaliativo ao contrário de uma pesquisa de caráter quantitativo, que se propõe apenas a avaliar dados numéricos; essa abordagem se baseia no estudo de crenças, significados e subjetividade (BOGDAN e BIKLEN, 1994). 
Os questionamentos deste trabalho surgiram devido ao fato de que o Curso de Licenciatura em Educação do Campo tem como princípios básicos a capacitação de professores para a docência em Ciências da Natureza para atuação nas séries finais do Ensino Fundamental e Ensino Médio. Sendo assim, por se tratar de um Curso de formação de professores e que irão atuar em escolas do campo, deveria haver a inserção da abordagem ambiental, de forma a se contextualizar o Ensino de Ciências com a realidade do educando, seu local de vida e atividades.

Para a análise da presença da Educação Ambiental em atividades de ensino, pesquisa e extensão foi realizada a coleta de dados por meio de entrevistas semiestruturadas com egressas da $1^{\text {a }}$ turma do Curso, com ingresso em 2014/1 e conclusão em 2017/2. Foi utilizado um roteiro de entrevista pré-estabelecido, com algumas perguntas relacionadas ao objetivo da pesquisa e outras que foram surgindo a partir da fala dos sujeitos ao longo da entrevista. As falas foram gravadas e posteriormente transcritas. Foram atribuídos códigos no lugar dos nomes (em ordem alfabética) de forma a se garantir o anonimato das participantes, sendo definidos os códigos de E1 a E6.

Demo (1995) define a entrevista semiestruturada como a atividade científica que permite ao pesquisador descobrir a realidade. Por sua vez, Minayo (1996) defende ser o fenômeno que permite aproximar os fatos ocorridos na realidade da teoria existente sobre o assunto analisado, a partir da combinação entre ambos. Já Trivinos (1987, p.146) esclarece que entre as principais características de uma entrevista semiestruturada estão: “[...] apoiar-se em teorias e hipóteses que se relacionam ao tema da pesquisa; descrever e explicar os fenômenos analisados para sua melhor compreensão; que o aluno/pesquisador seja atuante no processo de coleta de informações."

Em seguida, os dados coletados a partir das entrevistas e consequentemente transcritos foram tratados por meio da metodologia da Análise Textual Discursiva. Segundo Moraes e Galiazzi (2006), a Análise Textual Discursiva se constitui em uma abordagem do tipo qualitativa, pois se caracteriza por se aprofundar na compreensão de fenômenos que se investiga a partir de uma análise rigorosa e criteriosa; a intenção não é testar hipóteses para comprová-las ou contestá-las ao final da pesquisa, mas compreender os termos investigados. Os autores descrevem ainda a Análise Textual 
Discursiva como uma abordagem de análise de dados que transita entre duas formas importantes de análise na pesquisa qualitativa, que são a análise de conteúdo e a análise de discurso (MORAES e GALIAZZI, 2006).

Segundo os mesmos autores (MORAES e GALIAZZI, 2006), essa análise é descrita como: um processo que se inicia com uma unitarização, em que os textos são separados em unidades de significado. A separação é realizada por trechos de elementos pesquisados nas entrevistas. Esses elementos poderão ser frases, pequenos trechos e até mesmo o parágrafo todo dependendo do significado do contexto. Essas unidades por si mesmas podem gerar outros conjuntos de unidades oriundas da interlocução empírica, da interlocução teórica e das interpretações feitas pelo pesquisador. Neste movimento de interpretação do significado atribuído pelo autor da pesquisa exercita-se a apropriação das palavras de outras vozes para compreender melhor o texto. Assim, depois da realização desta unitarização, que deve ser realizada com intensidade e profundidade, faz-se a articulação de significados semelhantes em um processo denominado categorização: "Neste processo, reúnem-se as unidades de significado semelhantes, podendo gerar vários níveis de categorias de análise” (MORAES e GALIAZZI, 2006, p.118).

A parte final da Análise Textual Discursiva é a Comunicação, na qual é realizada a análise do discurso através de textos que expliquem as categorias criadas. É neste sentido que se vai clareando a comunicação dos achados. Para Moraes e Galiazzi (2006), é neste movimento de interpretação dos significados atribuídos pelo pesquisador que se exercita a apropriação das palavras de outras vozes para compreender melhor o contexto. Destaca-se que este trabalho é parte de um Trabalho do Conclusão de Curso e uma das categorias criadas no processo de análise, "Tempo Comunidade e a relação interdisciplinar com a Educação Ambiental" será apresentada e discutida a seguir.

\section{TEMPO COMUNIDADE E A RELAÇÃO INTERDISCIPLINAR COM A EDUCAÇÃO AMBIENTAL}

O Curso de Licenciatura em Educação do Campo da Universidade Federal de Catalão (EDUCampo/UFCAT) é estruturado em dois momentos pedagógicos: o Tempo Comunidade (TC), compreendendo a vivência em comunidades rurais, e o Tempo Universidade (TU), período em que são realizadas as aulas presenciais na Universidade 
(UFG, 2017). O objetivo do Curso de Licenciatura em Educação do Campo é formar educadores para a docência em escolas do campo a partir da articulação do ensino de graduação (TU) com a vivência na comunidade (TC) com o intuito de promover uma visão ampla de educação. Ambas etapas dessa proposta de educação (Pedagogia de Alternância) buscam promover aprendizados e conhecimentos.

O Tempo Universidade e Tempo Comunidade constituem carga horária na grade curricular do curso e se referem ao estudo teórico ou prático das disciplinas dos componentes curriculares. Segundo o Projeto Pedagógico de Curso (UFG, 2017), as ações desenvolvidas no Tempo Comunidade devem ser previstas e desenvolvidas sob responsabilidade dos formadores.

Segundo Silva et al. (2019), a escola do campo é caracterizada pela valorização do contexto social, político, econômico e cultural no qual está inserida. E o Tempo Comunidade permite aos futuros professores conhecerem a realidade dos alunos do campo, de forma a posteriormente poderem realizar a articulação entre o Ensino de Ciências e a realidade de vida destes alunos. Sendo assim, o Tempo Comunidade se constitui em um espaço único e rico na formação dos futuros professores do campo, e possibilita relacionar os conhecimentos científicos e teóricos trabalhados nas diversas disciplinas do currículo com a prática em campo.

Em relação à formação dos professores de Ciências para escolas do campo, Fonseca e Bierhalz (2016) salientam que é necessária a qualificação desses profissionais, uma vez que a Educação do Campo é uma área nova de ensino e pesquisa no cenário da Educação brasileira e demanda docentes preparados para trabalharem nesta realidade, que saibam relacionar o estudo teórico com vivências práticas e reinterpretar os modelos tradicionais de ensino, utilizando diferentes metodologias.

Desta forma, destaca-se que uma das maneiras de se garantir um Ensino de Ciências diferenciado e a contextualização do mesmo com a realidade do aluno é por meio da articulação com a Educação Ambiental, uma vez que essa permite a construção do conhecimento científico para a transformação da realidade. Mousinho (2003, p. 158) define a Educação Ambiental como um:

Processo em que se busca despertar a preocupação individual e coletiva para a questão ambiental, garantindo o acesso à informação em linguagem adequada, contribuindo para o desenvolvimento de uma consciência crítica e 
estimulando o enfrentamento das questões ambientais e sociais. Desenvolvese num contexto de complexidade, procurando trabalhar não apenas a mudança cultural, mas também a transformação social, assumindo a crise ambiental como uma questão ética e política.

Neste trabalho, buscou-se investigar as ações/atividades desenvolvidas durante o Tempo Comunidade e analisar a importância da Educação Ambiental para o Ensino de Ciências na Educação do Campo e, para isso, analisou-se as ações/atividades desenvolvidas no Tempo Comunidade na percepção das egressas da primeira turma do Curso. Assim, durante a entrevista, a Educação Ambiental apareceu de forma clara nas descrições das atividades realizadas no Tempo Comunidade. Ressalta-se que tais atividades são propostas pelo conjunto de professores que ministram disciplinas no período, ou seja, são atividades propostas de forma multidisciplinar, englobando as disciplinas pedagógicas de formação de professores e as disciplinas específicas da área de Ciências da Natureza e da Educação do Campo:

No Tempo Comunidade praticamente todos o TC a gente visitou comunidades, assentamentos, comunidades locais. Inclusive tivemos um trabalho que foi realizado em uma agroindústria e em uma comunidade de agricultura familiar, para fazer um paralelo entre os tipos de produção. Em todos os trabalhos tivemos um conhecimento aprofundado dos parâmetros entre um tipo de produção mais industrial (comodities), que agride o meio ambiente e uma cultura de subsistência (agricultura familiar), que trabalha de forma natural, conservadora e praticam uma agricultura tradicional. (E2).

Nas visitas que fizemos a EFAORI a Agrofava, no Tempo Comunidade nós trabalhamos a contaminação da água realizando pesquisas e trabalhamos com plantas medicinais também (E4).

$\mathrm{Na}$ fala de E2 podemos observar a citação uma atividade realizada durante o Tempo Comunidade em que foi trabalhada a dicotomia entre o agronegócio e a agricultura familiar (agricultura tradicional). Percebe-se que na atividade foi proposto o tensionamento da relação entre a Educação Ambiental e o Ensino de Ciências através do uso dos agrotóxicos e a contaminação do solo e da água, que é citada por E4 no excerto 2. Tal temática poderia ser trabalhada por exemplo com uma turma de $3^{\circ}$ Ano de Ensino Médio, de forma a se discutir a Química Orgânica: "Pensar o Ensino de Ciências perpassando pela discussão das questões locais, da cultura regional e dos aspectos pertinentes às vivências dos sujeitos pertencentes ao campo, significa reconhecer que o Ensino e a Educação do Campo ocorrem por meio de seu contexto, dos sujeitos, das histórias de vida e de luta" (FONSECA e BIERHALZ, 2016). Mais que isso, significa 
pensar o Ensino de Ciências como conhecimento para a melhoria da qualidade de vida dos sujeitos do campo.

Tenório et al. (2019) afirmam que:

Educação do Campo precisa ser pensada no campo e para os sujeitos do campo, levando em consideração suas experiências sociais, econômicas, culturais e políticas, já que é esse tipo de educação que valoriza a diversidade que necessita ser trabalhada na sociedade. E o ensino de Ciências é capaz de melhorar as condições sociais desses sujeitos em todos os âmbitos, garantindo-lhes, desse modo, o respeito e a dignidade dos povos do campo (TENÓRIO et al., 2019, p. 177).

O regime de alternância dos Cursos de Licenciatura em Educação do Campo é um diferencial das demais licenciaturas, pois permite que os licenciandos se engajem em ações de ensino que possibilitem a articulação entre ação (observação), pensamento e nova ação (BRICK et al., 2014). No entendimento de Cordeiro (2009, p. 60):

[...] a pedagogia da alternância oferece aos jovens do campo a possibilidade de estudar, de ter acesso ao conhecimento não como algo dado por outrem, mas como um conhecimento conquistado, construído a partir da problematização de sua realidade, problematização essa que passa pela pesquisa, pelo olhar distanciado do pesquisador sobre o seu cotidiano.

As entrevistadas reforçaram a importância do Tempo Comunidade no processo de formação inicial docente; em suas respostas, demonstraram que esse é um dos principais momentos em que a relação teoria e prática é proporcionada e a Educação Ambiental aparece de forma clara, pois as discussões perpassam a realidade do campo e seus modos de produção, além de ser um momento para que elas refletissem sobre como o Ensino de Ciências poderia ser associado com a realidade observada. Desta forma, E3 cita a importância da Educação Ambiental na formação de professores da área de Ciências da Natureza, reforçando a ligação entre Educação do Campo x Ensino de Ciências x Educação Ambiental:

[...] eu acho que nos dias atuais a questão ambiental vem em primeiro lugar, o professor em específico, nós da área de Ciências da Natureza temos que estar sempre ligados e antenados nessa temática para conscientizar os alunos. Para isso temos que estar cada dia mais e mais envolvidos com a questão ambiental (E3).

Ao mesmo tempo, a questão parece ter sido trabalhada de maneira transversal ao currículo das egressas:

A questão ambiental foi abordada através dos trabalhos realizados durante o

Tempo Comunidade de maneira interdisciplinar. (E2) 
Almeida (2006) explica que os temas transversais contribuem para a formação integral da pessoa e para a construção de uma sociedade mais justa, mais humana e solidária, o que não seria possível alcançar apenas com a mera exposição dos conteúdos das disciplinas, sem conexão com o contexto sociocultural. Nesse aspecto, Arroyo, Caldart e Molina (2004) já argumentavam que a Educação do Campo deve estar associada à manutenção de condições para a vida no campo, construindo formas, espaços e relações diferenciadas, com base no ofício coletivo, na articulação entre trabalho e estudo e entre teoria e prática. Através dos excertos apresentados, percebe-se que as egressas demonstraram que a Educação Ambiental surge exatamente com base no ofício coletivo, no meio de produção, relacionando a teoria trabalhada no Tempo Universidade e a prática reflexiva do Tempo Comunidade.

Segundo Netto e Schultz (2017), tanto a Educação Ambiental quanto a Educação do Campo propõem uma pedagogia que visa promover a educação contextualizada localmente, onde se situam os sujeitos e atores do processo educativo, o que permite buscar soluções para os problemas sociais e ambientais locais, promovendo transformações para a sustentabilidade. A Educação do Campo, em conjunto com a Educação Ambiental, tem se mostrado como estratégia para transformar o espaço rural brasileiro, resgatando-o como espaço de produção, mas também de relações socioculturais, e com a natureza (MOLINA e JESUS, 2004).

Diante disso, Jacobi e Luzzi (2004, p. 11) afirmam que a Educação Ambiental é muito mais que a conjunção de enfoques interdisciplinares, métodos sistêmicos ou a elaboração de áreas integradas. Para esses autores, a Educação Ambiental reclama a produção de um saber ambiental que problematize as diversas disciplinas, gerando novos conhecimentos, novas maneiras de ver a realidade. Ou seja, os autores acreditam que a Educação Ambiental permite o entrelaçar de conhecimentos das diversas disciplinas, promovendo uma nova maneira de rever o mundo. Para Santomé (1998, 253):

\footnotetext{
A interdisciplinaridade é um objetivo nunca completamente alcançado e por isso deve ser permanentemente buscado. Não é apenas uma proposta teórica, mas, sobretudo uma prática. Sua perfectibilidade é realizada na prática; na medida em que são feitas experiências reais de trabalho em equipe, exercitam-se suas possibilidades, problemas e limitações.
} 
Assim, percebe-se pelas falas das entrevistadas que o Tempo Comunidade tem proporcionado a tão difícil e buscada interdisciplinaridade por meio da realização de visitas com enfoque na Educação Ambiental. Tal trabalho parece permitir a reflexão sobre como relacionar os conhecimentos de Ensino de Ciências com a realidade de vida e o contexto dos alunos da Educação do Campo (povos do campo).

Para isso, as várias disciplinas do semestre letivo se integram em um trabalho comum visando a relação teoria e prática. Uma das visitas citadas pelas egressas foi na EFAORI (Escola Família Agrícola de Orizona), que é uma instituição que trabalha a alternância e a interdisciplinaridade. Em entrevista é destacado que teoria e prática caminham juntas naquela instituição e acredita-se que isso possa contribuir para bons resultados:

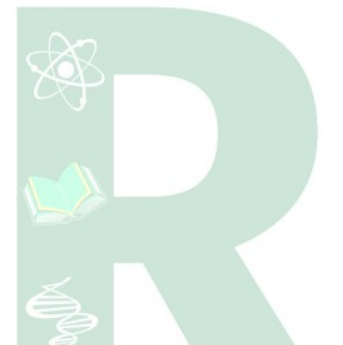

Na EFAORI trata se muito da importância da Educação Ambiental em sala de aula e o que eles aprendem em sala de aula (teoria), aplica-se na prática. Lá tem hortas que eles cultivam, tem os animais que eles criam. Os alunos nos relataram em entrevista que eles ficam quinze dias na EFAORI e quinze dias na casa deles e que durante esses quinze dias eles aplicam essa prática também no sítio deles (todos moram no sitio) e auxiliam os seus pais a continuarem usando desse método que eles aprendem na EFAORI. O mesmo é totalmente voltado para a preservação do meio ambiente. (E6)

Além de apontarem a importância de se relacionar a teoria e a prática, as egressas a todo momento estabeleceram uma correlação entre pequenos agricultores/agronegócio, temática na qual a Educação Ambiental está sempre em pauta, bem como o Ensino de Ciências. As egressas deixaram claro que a cada Tempo Comunidade o tema era diferente. Destaca-se que a diversificação dos temas no Tempo Comunidade permite aos futuros professores conhecerem mais espaços voltados para a Educação do Campo, o que proporcionará a eles mais conhecimentos e, consequentemente, mais facilidade de associação das diversas realidades do aluno com o Ensino de Ciências, de forma a contribuir com a aprendizagem e a interpretação do mundo para o aluno.

Como apresentam os relatos das egressas, trabalhou-se com discussões sobre a qualidade da água, animais, plantas medicinais, agricultura familiar versus agronegócio, agrotóxicos, produtos orgânicos, dentre outros:

Trabalhamos com as plantas medicinais no início, nos primeiros TC, falando de sua importância para a saúde. Acredito que isso também contribui para a questão ambiental. Teve também o TC em que realizamos uma visita a 
EFAORI que é uma escola agrícola, onde eles trabalham com a agricultura familiar. Nós conhecemos o trabalho deles com horta orgânica, com os animais. Me recordo também da visita a Agrofava que fizemos na mesma ocasião da visita a EFAORI para contrastar a realidade da Agricultura Familiar e do Agronegócio. (E3).

Quando fomos visitar a AGROFAVA falou-se de sementes transgênicas, que é um tipo de semente com a qual o grupo trabalha e que em sua maioria o agronegócio trabalha. Então discutiu-se os maleficios que a semente transgênica poderia trazer para a natureza e para os seres humanos [...]. Na ocasião, para contrastar com a visita anterior, visitamos um assentamento onde a família trabalhava com agricultura familiar. Em discussão perguntamos então a pequena agricultora se eles fazem ou não o uso de defensivos em sua agricultura. (E6).

A partir da fala da entrevistada E3, pode-se observar novamente a questão dos agrotóxicos sendo apresentada, o que permite aos futuros professores refletirem sobre a importância de se trabalhar com esse tema com os alunos do campo, seja na Química Orgânica, na Biologia, ou por meio da discussão sobre produtos orgânicos e até mesmo sobre o uso dos transgênicos. As egressas citaram ainda a importância da Educação Ambiental na formação inicial docente na área de Ciências da Natureza.

A fala das entrevistadas reforça a ideia de autores de que é preciso obter conhecimento para além da literatura, como bem afirma o ditado popular: "colocando a mão na massa". As atividades realizadas nos Tempos Comunidade, principalmente nos estudos de campo sobre a comunidade rural, devem ser compreendidas também como contexto de produção de conhecimento, como "situação gnosiológica" (FREIRE, 2006), "práxis criativa" (PIMENTA e LIMA, 2010) condicionada pela organização do espaçotempo escolar e da relação escola-comunidade.

É neste sentido que o Tempo Comunidade, em articulação com contextos que estejam pautados no currículo, pode fazer com que a contribuição de uma escola com a transformação social não pareça tão utópico, mas sim como "inédito viável” (FREIRE, 2006) no qual o licenciando poderia tomar conhecimento não apenas a partir da literatura sobre experiências nesse sentido, mas participando e aprendendo o que ainda está tácito para quem participou desses processos e com desafios cujo enfrentamento ainda são inéditos e inerentes ao contexto local.

Caldart (2011) reforça o consenso das críticas das concepções de Educação do Campo à docência individual, disciplinar e afastada das questões da realidade:

O grande desafio curricular não é nessa visão [da Educação do Campo] apenas garantir momentos de contextualização dos conteúdos, mas sim o de 
juntar teoria e prática, integrando, em uma mesma totalidade de trabalho pedagógico, não somente disciplinas ou conteúdos entre si, mas estudo e práticas sociais, fundamentalmente práticas de trabalho e de organização coletiva dos estudantes, totalidade inserida na luta pela criação de novas relações sociais e na formação onilateral dos trabalhadores que lhe corresponde (CALDART, 2011, p. 114).

As entrevistadas confirmaram essa realidade de que o Curso de Licenciatura em Educação do Campo da UFCAT tem garantido essa prática integrada e contextualizada, na qual teoria e prática caminham juntas e conseguem permear harmoniosamente a maioria das disciplinas, enfatizando inclusive o papel da Educação Ambiental neste contexto.

Foi em uma comunidade em que nós trabalhamos o meio ambiente, o solo, onde foi coletada amostra do solo, coletou-se amostra de água que os moradores consumiam (E1).

Sim, desenvolvemos um trabalho sobre os animais e as plantas relacionadas a questão ambiental. (E5).

Nas falas citadas, percebe-se que o Tempo Comunidade permite a articulação entre teoria e prática, entre Ensino de Ciências e contexto, tudo isso baseado numa abordagem da Educação Ambiental. Assim, observa-se indícios de que os professores em formação estão se apropriando de um conhecimento científico contextualizado com as questões do campo e com a questão ambiental e, dessa forma, preparando-se para atuarem de acordo com a realidade de seus futuros alunos.

Conforme os relatos das egressas, as mesmas desenvolveram os trabalhos em comunidades sempre pautadas no que era visto/trabalhado/estudado nas disciplinas do Curso; para a/o análise/estudo proposta/o para o Tempo Comunidade as alunas tinham que mobilizar os conhecimentos científicos aprendidos no Tempo Universidade e logo foi possível estabelecer uma relação entre teoria e prática, o que é imprescindível para a construção do conhecimento científico contextualizado e crítico.

\section{CONSIDERAÇÕES FINAIS}

Este trabalho buscou avaliar a relação entre Educação do Campo, Ensino de Ciências da Natureza e a Educação Ambiental. Por meio da análise das respostas das egressas do Curso de Licenciatura em Educação do Campo da Universidade Federal de Catalão (EDUCampo/UFCAT) percebeu-se que o Tempo Comunidade foi apontado como o principal meio de se trabalhar a interdisciplinaridade e a contextualização do 
conhecimento científico através da Educação Ambiental, por exemplo, por meio de visitas de campo.

Nas entrevistas, as egressas do Curso afirmaram que as temáticas trabalhadas no Tempo Comunidade ao longo do Curso propiciaram a discussão de problemas ambientais no contexto autêntico de vivência dos povos do campo, sempre interrelacionando a teoria estudada no Tempo Universidade e a prática no campo. Para isso, percebe-se a importância dos conhecimentos científicos para a discussão de tais problemas ambientais e sociais.

Além disso, pôde-se observar que esse espaço de formação permitiu às futuras professoras que conhecessem a realidade de diversas comunidades campesinas, o que se acredita que tenha sido de grande importância para a sua formação, uma vez que essa vivência deve ter fornecido bagagem a elas, de forma que ao chegarem na escola do campo enquanto professoras possam realizar a associação entre o Ensino de Ciências e a realidade do aluno do campo, tendo como base a Educação Ambiental.

Em conclusão, quando se questionou às entrevistadas sobre as atividades/discussões vivenciadas durante o Tempo Comunidade, em unanimidade todas citaram que a Educação Ambiental permeou as atividades, favorecendo a contextualização do conhecimento científico com a realidade dos povos do campo. Elas citaram momentos nos quais a Educação Ambiental foi abordada, destacando ainda que em todos os Tempos Comunidade trabalhou-se a temática de maneira interdisciplinar, abordando não só as disciplinas científicas, mas também as articulando com os conhecimentos pedagógicos e da Educação do Campo.

\section{REFERÊNCIAS}

ALMEIDA, T. J. B. Abordagem dos temas transversais nas aulas de ciências do ensino fundamental, no Distrito de Arembepe, município de Camaçari-BA. Candombá Revista Virtual, v. 2, n. 1, p. 1-13, jan - jun 2006.

ARROYO, M. G Políticas de formação de educadores (as) do Campo. Caderno Cedes, Campinas, vol. 27, nº 72, pp.157-176, maio/ago. 2007.

ARroyo, M. G.; CALDART, R. S.; MOLINA, M. C. Por uma educação do campo. Petrópolis: Vozes, 2004. 
AZEVEDO, M. A. Política de Educação do Campo: concepções processos e desafios. In: NETO, Antonio Cabral et al. Pontos e contrapontos da política educacional: uma leitura contextualizada de iniciativas governamentais. Brasília: Liber Livros, 2007.

BOGDAN, R., BIKLEN, S. K. Investigação qualitativa em educação. Porto, Portugal: Porto Editora, LTDA, 1994.

BRICK, E. M., PERNAMBUCO, M. M. C. A., SILVA, A. F. G., DELIZOICOV, D. Paulo Freire: interfaces entre Ensino de Ciências Naturais e Educação do Campo. In MOLINA, M. C. (Org.). Licenciaturas em Educação do Campo e o ensino de Ciências Naturais: desafios à promoção do trabalho docente interdisciplinar. Brasília: Editora MDA, 2014. pp. 23-59.

BRITTO, N. Z., SILVA, T. G. R. Educação do Campo: formação em ciências da natureza e o estudo da realidade. Educação \& Realidade, v. 40, n 3, 763-784, 2015.

CALDART, R. S. Por uma educação do campo: traços de uma identidade em construção. In: Educação do campo: identidade e políticas públicas - Caderno 4. Brasília: Articulação Nacional "Por Uma Educação Do Campo”, 2002.

CALDART, R. S. O MST e a escola: concepção de educação e matriz formativa. In: CALDART, R. S. (Org.). Caminhos para transformação da escola: reflexões desde práticas da licenciatura em Educação do Campo. São Paulo: Expressão Popular, 2011.

CORDEIRO, G. N. K. A relação teoria-prática do curso de formação de professores do campo na UFPA. 2009. Tese (Doutorado em Educação) - Universidade Federal do Rio Grande do Norte, Faculdade de Educação, Natal, 2009.

DEMO, P. Metodologia científica em ciências sociais. 3. ed. São Paulo: Atlas, 1995. ENISWELER, E. C., KLIEMANN, C. R. M., STRIEDER, D. M. O Ensino de Ciências na Educação do Campo: uma pesquisa em dissertações e teses. In Anais do V Seminário Nacional Interdisciplinar em Experiências Educativas - V SENIEE. Unioeste, 2015.

FONSECA, E. M.; BIERHALZ, C. D. K. Discutindo articulações entre ensino de Ciências e Educação do Campo através da análise dos cadernos. Revista Brasileira de Educação do Campo, v. 1, n. 2, p. 255-278, 2016.

FREIRE, P. Pedagogia da esperança. 13. ed. Rio de Janeiro: Paz e Terra, 2006

JACOBI, P.; LUZZI, D. Educação e Meio Ambiente - um diálogo em ação. 2004. Anais... 27 Reunião Anual da ANPEd. Disponível em: http://27reuniao.anped.org.br/gt22/t2211.pdf. Acesso em: 08 de setembro de 2020.

JESUS, J. N. A pedagogia da Alternância e o debate da educação no/do campo no estado de Goiás. Revista NERA. Presidente Prudente, SP. Ano14, nº 18, p. 07 - 20. 2011. 
LEITE, S. C. Escola rural: urbanização e políticas educacionais. 2. ed. São Paulo: Cortez, 2002.

LIMA, M. E. C. C., PAULA, H. F. E., SANTOS, M. L. B. Ciências da vida e da natureza no curso de Licenciatura em Educação do Campo. In ROCHA, M. I. A., MARTINS, A. A. (Orgs.). Educação do Campo: desafios para a formação de professores (pp. 107-118). Belo Horizonte: Editora Autêntica, 2009.

LOPES, E. A. M., BIZERRIL, M. X. A. Vídeo e Educação do Campo: novas tecnologias favorecendo o Ensino de Ciências interdisciplinar. In MOLINA, M. C. (Org.). Licenciaturas em Educação do Campo e o ensino de Ciências Naturais: desafios à promoção do trabalho docente interdisciplinar. Brasília: Editora MDA, 2014. pp. 201-229.

LOUREIRO, C. F. B. A Educação Ambiental no Brasil. Proposta pedagógica. Salto para o Futuro, Brasília, ano 18, boletim 1, março de 2008. Disponível em: < http://forumeja.org.br/sites/forumeja.org.br/files/Educa\%C3\%A7\%C3\%A3o\%20Ambie ntal\%20no\%20Brasil\%20(texto\%20basico).pdf>. Acesso em: 05 de outubro de 2020.

MELO, R. J., ADAMS, F. W., NUNES, S. M. T. Concepções da importância do Ensino de Ciências na educação básica por licenciandos de um curso de Educação do Campo. Revista Brasileira de Educação no Campo, v. 5, p. 1 -21, 2020. Disponível em: https://sistemas.uft.edu.br/periodicos/index.php/campo/article/view/7240. Acesso em: 05 de outubro de 2020.

MINAYO, M. C. S. O desafio do conhecimento: pesquisa qualitativa em saúde. 3. ed. São Paulo: Hucitec/Rio de Janeiro: Abrasco, 1996.

MOLINA, M. C.; JESUS, S. M. Por uma Educação do Campo. Brasília, 2004.

MOLINA, M. C. Contribuições das Licenciaturas em Educação do Campo para as Políticas de Formação de Educadores. Educ. Soc. vol.38, no.140, p. 587-609, Campinas July/Sept. 2017.

MOLINA, M. C.; FREITAS, H. C. A. Avanços e desafios na construção da educação do campo. Em Aberto, vol. 24, número 85, 17-31, 2011.

MORAES, R., GALIAZZI, M. C. Análise textual discursiva: processo reconstrutivo de múltiplas faces. Ciência \& Educação, v. 12, n. 1, p. 117-128, 2006.

MOUSINHO, P. Glossário. In: TRIGUEIRO, A. (Coord.) Meio ambiente no século 21. Rio de Janeiro: Sextante, 2003.

MUNARIM, A. Os campos da pesquisa em Educação do Campo: espaço e território como categorias essenciais. In: MOLINA, M.; C. Educação do Campo e pesquisa: questões para reflexão. Brasília/MDA, 2006. 
NETTO, D., SCHULTZ, G., Aproximações entre a educação do campo e a educação ambiental nos centros familiares de formação por alternância. Revista de Educação, Ciência e Tecnologia, v. 6, n. 2, p. 1 - 12, 2017.

PIMENTA, S. G.; LIMA, M. S. L. Estágio e docência. 5. ed. São Paulo: Cortez, 2010.

RODRIGUES, H. C. C., BONFIM, H. C. C. A Educação do Campo e seus aspectos legais. EDUCERE XIII Congresso Nacional de Educação, IV Seminário Internacional de Representações Sociais Subjetividade e Educação - SIRSSE, VI Seminário Internacional Sobre Profissionalização Docente (SIPD/CÁTEDRAUNESCO). p. 1374 1387. 2017.

SANTOMÉ, J. T. Globalização e Interdisciplinaridade: o currículo integrado. Porto Alegre: ArtMed, 1998.

SILVA, F. N. S., LIMA, L. R. F. C., MORADILLO, E. F., MASSENA, E. P. Educação do campo e ensino de ciências no Brasil: uma revisão dos últimos dez anos. R. Bras. Ens. Ci. Tecnol., Ponta Grossa, v. 12, n. 1, p. 221-239, jan./abr. 2019.

TENÓRIO, W. D., FORMIGOSA, M. M., ROCHA, C. G. S., SANTANA, R. H. S. A Formação E Atuação Docente Na Disciplina De Ciências Em Escolas Do Campo Na Amazônia Paraense. Revista Insignare Scientia, vol. 2, n. 4., p. 158-179, Set./Dez. 2019. Disponível em: https://periodicos.uffs.edu.br/index.php/RIS/article/view/11021. Acesso em: 08 de setembro de 2020.

TORALES, M. A. A inserção da Educação Ambiental nos currículos escolares e o papel dos professores: da ação escolar à ação educativo-comunitária como compromisso político-pedagógico. Revista Eletrônica do Mestrado em Educação Ambiental, Rio Grande/RS, v. especial, p. 1-17, p. 1-17, mar. 2013.

TRIVINOS, A. N. S. Introdução à pesquisa em ciências sociais: a pesquisa qualitativa em educação. São Paulo: Atlas, 1987.

UNIVERSIDADE FEDERAL DE GOIÁS. REGIONAL CATALÃO. Projeto Pedagógico do Curso de Licenciatura em Educação do Campo. 2017. www.fja.edu.br/candomba/pdfs/TeresaAlmeida2006v2n1.pdf. Acessado em: 08 de setembro de 2020.

Agradecimentos: Ao Programa Bolsas de Licenciatura da UFG (PROLICEN). 